\title{
Serum levels of astroglial S100- beta and neuron-specific enolase in hepatic encephalopathy patients
}

A. Saleh, ${ }^{1}$ L. Kamel, ${ }^{1}$ A. Ghali, ${ }^{2}$ A. Ismail ${ }^{2}$ and H. El Khayat ${ }^{2}$

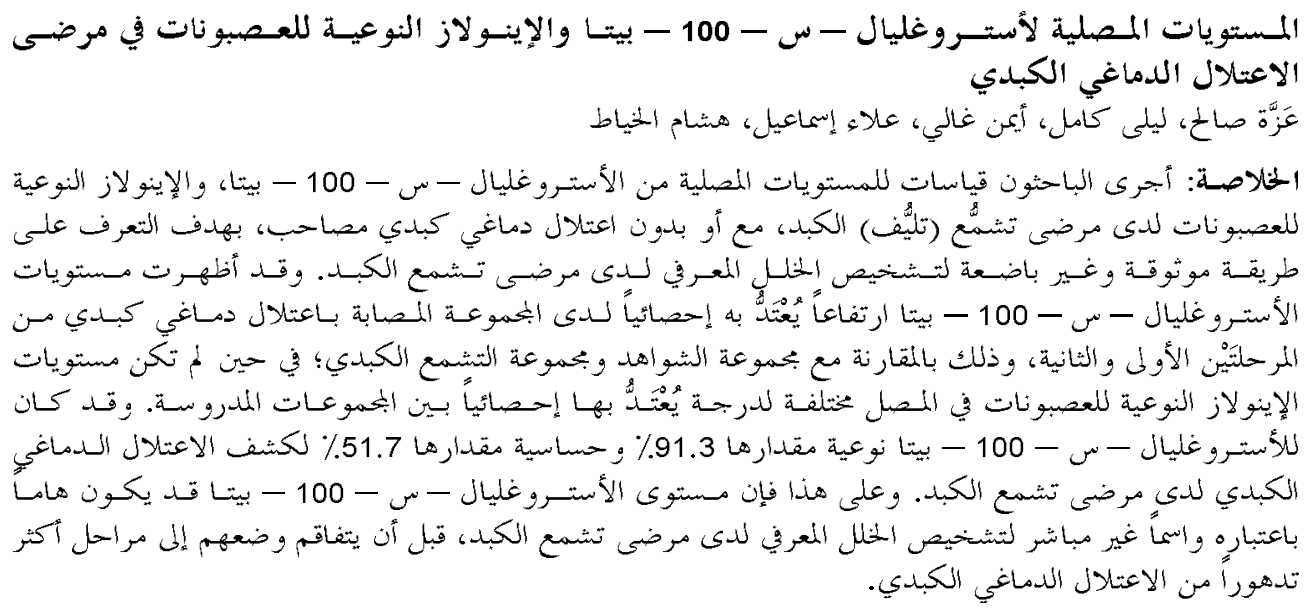

ABSTRACT To find a reliable, noninvasive method for the diagnosis of cognitive impairment in patients with hepatic cirrhosis we measured serum levels of astroglial $\mathrm{S} 100 \beta$ and neuron-specific enolase in cirrhotic patients with and without hepatic encephalopathy (HE). S100 $\beta$ levels showed a significant increase in groups with HE stage 1 and 2 compared to both control and cirrhosis patients. However serum neuron-specific enolase levels were not significantly different between the studied groups. S100ß levels had a specificity of $91.3 \%$ and sensitivity of $51.7 \%$ for detection of HE from cirrhosis. Serum S100ß may be a useful surrogate marker for the diagnosis of mild cognitive impairment in cirrhotic patients before they progress to more advanced stages of HE.

Concentrations sériques de la protéine astrogliale S100-bêta et de l'énolase neurospécifique dans l'encéphalopathie hépatique

RÉSUMÉ À la recherche d'une méthode diagnostique fiable et non invasive du déficit cognitif associé à la cirrhose hépatique, nous avons mesuré les concentrations sériques de la protéine astrogliale S100- $\beta$ et de l'énolase neurospécifique (NSE) chez des patients cirrhotiques avec et sans encéphalopathie hépatique (EH). II a été observé une augmentation significative des taux de S100- $\beta$ dans les groupes atteints d'EH de stade 1 et 2 par rapport tant aux témoins qu'aux patients cirrhotiques. Toutefois, les concentrations sériques de NSE n'ont laissé apparaître aucune différence significative entre les groupes étudiés. Les taux de S100- $\beta$ font preuve d'une spécificité de $91,3 \%$ et d'une sensibilité de $51,7 \%$ pour la détection de l'EH à partir du sérum de patients cirrhotiques. La protéine $S 100-\beta$ sérique peut se révéler un marqueur de remplacement utile dans le diagnostic du déficit cognitif léger chez le cirrhotique avant une évolution vers un stade d'EH plus avancé.

${ }^{1}$ Department of Clinical Chemistry; ${ }^{2}$ Department of Tropical Medicine, Theodor Bilharz Research Institute, Cairo, Egypt (Correspondence to A. Saleh: azzasaleh@hotmail.com).

Received: 06/07/05; accepted: 09/11/05 


\section{Introduction}

Cirrhosis of the liver is associated with a decreased health-related quality of life, whether physically (especially at advanced stages), mentally (subclinical encephalopathy) or both (overt hepatic encephalopathy), independent of the severity of the disease [1]. Hepatic encephalopathy (HE) is a neuropsychiatric syndrome observed in patients with liver failure and/or portal-systemic bypass. It is frequently considered to be a complex syndrome involving several behavioural manifestations, such as personality changes, memory disorders, disorientation, flapping tremor, shortened attention span, lack of muscle coordination, bradykinesia, somnolence and changes in sleep patterns [2]. However, inconsistent results regarding the behavioural, metabolic and neurochemical characteristics indicate that the pathogenesis and pathophysiology of the syndrome are still obscure [3].

$\mathrm{S} 100 \beta$ is a member of the $\mathrm{S} 100$ family of proteins that was termed "S100" because it was soluble in $100 \%$ saturated ammonium sulfate solution [4]. S100 $\beta$ is an acidic protein with a molecular weight of $21 \mathrm{kDA}$ existing as a homodimer consisting of 2 beta subunits, and a biologic half-life of 0.5 hour $[5,6]$. $\mathrm{S} 100 \beta$ is produced primarily by astrocytes and exerts autocrine and paracrine effects on glia, neurons, and microglia [7]. S100 $\beta$ normally is low or undetectable in serum; however, elevated serum levels have been detected in a number of neuropathological conditions [8]. It is thought to be released from glial cells via a mechanism similar to that governing the secretion or release of other factors such as ciliary neurotrophic factor, interleukin-1 $\alpha$ and $1 \beta$, or human endothelial growth factor [9].
The neuronal form of intra-cytoplasmic glycolytic enzyme enolase is called neuron-specific enolase (NSE) and it has been shown to be located in neurons and neuroectodermal cells $[10,11]$. After traumatic brain injury in adults, NSE has been found in the cerebrospinal fluid (CSF) [12] and serum [13], an indicator of impairment of the integrity of the blood-brain barrier (BBB). Astrocytic functions modulate neuronal ammonia toxicity because ammonia is detoxified mainly via astrocytic glutamine synthesis [14]. Abnormal BBB function frequently occurs with brain damage. S100 $\beta$ levels sometimes rise in the absence of neuronal damage, suggesting that S100 $\beta$ is a marker of $\mathrm{BBB}$ rather than neuronal damage, although in a variety of neurological diseases, the 2 brain-specific proteins, $\mathrm{S} 100 \beta$ and NSE, are released systemically [15]. In addition, $\mathrm{S} 100 \beta$ in serum is an early marker of BBB openings that may precede neuronal damage and may influence therapeutic strategies; this is explained by the fact that astrocytes form part of the BBB and the increase in its permeability in HE due to acute liver failure may in part be correlated to impaired astrocytic functions [16].

In clinical conditions in which an impairment of the BBB and/or astrocytic activation are implicated in the pathophysiology, elevated levels of S100 $\beta$ and NSE in serum and cerebrospinal fluid (CSF) have been reported. NSE and S100 $\beta$ are brainspecific, and their presence in the serum is a specific indicator for neuronal and astroglial cell death, respectively [17]. The aim of the present work in Cairo, Egypt, was to investigate the diagnostic efficiency of serum S100 $\beta$ and NSE as biomarkers of early cognitive impairment in patients with cirrhosis. 


\section{Methods}

\section{Patients}

There were 52 participants in the study, divided into 3 groups:

- 14 patients with cirrhosis but without encephalopathy, with a mean age of 51.0 [standard deviation (SD) 3.5] years and male/female ratio $7 / 7$.

- 29 patients with HE with underlying cirrhosis. These were further subdivided into 18 patients with HE stage 1, mean age 50.3 (SD 8.9) years, male/female ratio $10 / 8$, and 11 with HE stage 2 , mean age 54.2 (SD 9.0) years, male/female ratio $6 / 5$. The prevalence of HE stage 1 and 2 in our HE group were $62.1 \%$ and $37.9 \%$, respectively.

- 9 healthy age- and sex-matched controls, with a mean age of 52.2 (SD 8.9) years and male/female ratio $5 / 4$.

The diagnosis of cirrhosis was confirmed by clinical criteria and sonography; while the diagnosis of hepatic encephalopathy was based on clinical criteria, and the severity of hepatic encephalopathy was based on the West Haven criteria for grading of mental status. This is based on changes of consciousness, intellectual function and behaviour [18]. Patients with preexisting neurological or psychiatric diseases other than hepatic encephalopathy, or sleep disorders were excluded.

The etiology of disease in the cirrhosis patients without $\mathrm{HE}$ was hepatitis $\mathrm{C}$ virus (HCV) infection in 10 patients and hepatitis $\mathrm{B}$ virus (HBV) infection in 4 patients. The Child-Pugh score was applied for grading of liver dysfunction in all patients. In this group, 7 cirrhotic patients were scored grade $\mathrm{B}$ and 7 were grade $\mathrm{C}$.

In the HE patients the etiology of liver cirrhosis was HCV in 20 patients, HBV in 5 patients, both HCV and HBV in 3 patients and autoimmune hepatitis in 1 patient. All
29 HE patients were scored Child-Pugh grade C. Precipitating factors for hepatic encephalopathy included haematemesis in 10 patients, spontaneous bacterial peritonitis in 8 patients, electrolyte disturbance and diuretics in 7 patients and paracentesis in 4 patients.

\section{Data collection}

Patients were subjected to the following: full history taking, general and abdominal examinations, abdominal ultrasonography, upper endoscopy and laboratory investigations.

Liver function tests, including serum aminotransferases, alkaline phosphatase, albumin, bilirubin, prothrombin time and prothrombin concentration, were measured by conventional methods. Seromarkers for HBV (hepatitis B surface antigen and hepatitis B core antibody) were assayed by enzyme-linked immunosorbent assay (ELISA) (Boehringer Mannheim) and for HCV by Murex version III ELISA (Murex Biotech, UK).

For determination of plasma ammonia levels we used an enzymatic ultraviolet-assay (Randox, UK).

Serum S100ß levels were determined by a commercially available ELISA kit (CanAg Diagnostics, Gothenburg, Sweden) which is a solid-phase non-competitive assay based on the sandwich technique for optimal clinical sensitivity, specificity and non-specific interference for determination of $\mathrm{S} 100 \beta \beta$ isoform. The assay is based on an antibody specific for the $S 100 \beta \beta$ dimer as catcher and HRP labeled monoclonal antibodies specific for $\mathrm{S} 100 \beta$ detection. The detection limit of this assay is $0.02 \mu \mathrm{g} / \mathrm{L}$.

The levels of serum NSE were determined by a commercially available ELISA kit (CanAg Diagnostics, Gothenburg, Sweden) based on 2 monoclonal antibodies directed against 2 separate antigenic 
determinants of the NSE molecule. The monoclonal antibodies bind to the $\gamma$-subunit of the enzyme and thereby detect both the $\gamma \gamma$ and the $\alpha \gamma$ form. The minimum detection limit is $1 \mu \mathrm{g} / \mathrm{L}$.

\section{Statistical analysis}

Numerical data were expressed as mean (SD). Multiple intergroup comparisons were made by using one-way ANOVA, post-hoc with Tukey-Kramer multiple comparisons test. Correlations were computed using Spearman's rank correlation coefficient. SPSS, version 10, was used for data analysis. Receiver operating characteristics (ROC) analysis was done using Analyse-it software. $P<0.05$ was considered significant.

\section{Results}

The results are tabulated in Tables 1 and 2 and graphically presented in Figures 1-3.

Table 1 shows the clinical characteristics of the 3 different groups of patients (cirrhosis, HE stage 1 and HE stage 2). Fetor hepaticus was present only in HE patients (15 patients stage 1 and 9 patients stage 2). Spider and palmar erythaema were present in 13 cirrhosis patients (18 patients in stage $1 \mathrm{HE}$ and in only 10 patients in stage $2 \mathrm{HE}$ ).

Patients with cognitive deficits showed significantly elevated serum S100 $\beta$ levels at $P<0.01$ in both groups, HE stage 1 [mean 0.248 (SD 0.12)] $\mu \mathrm{g} / \mathrm{L}]$ and HE stage 2 [mean $0.311(\mathrm{SD} 0.12) \mu \mathrm{g} / \mathrm{L}$ ], as compared

\begin{tabular}{|c|c|c|c|c|c|c|}
\hline \multirow[t]{2}{*}{ Characteristic } & \multicolumn{2}{|c|}{$\begin{array}{c}\text { Cirrhosis } \\
(n=14)\end{array}$} & \multicolumn{2}{|c|}{$\begin{array}{c}\text { Hepatic } \\
\text { encephalopathy } \\
\text { stage } 1 \\
(n=18)\end{array}$} & \multicolumn{2}{|c|}{$\begin{array}{c}\text { Hepatic } \\
\text { encephalopathy } \\
\text { stage } 2 \\
(n=11)\end{array}$} \\
\hline & No. & $\%$ & No. & $\%$ & No. & $\%$ \\
\hline Fetor hepaticus & 0 & 0 & 15 & 83.3 & 9 & 81.8 \\
\hline $\begin{array}{l}\text { Spider and palmar } \\
\text { erythaema }\end{array}$ & 13 & 92.9 & 18 & 100.0 & 10 & 90.9 \\
\hline Loss of muscle mass & 9 & 64.3 & 12 & 66.7 & 8 & 72.7 \\
\hline Jaundice & 4 & 28.6 & 6 & 33.3 & 4 & 36.4 \\
\hline Pallor & 4 & 28.6 & 5 & 27.8 & 5 & 45.5 \\
\hline Lower limb oedema & 8 & 57.1 & 15 & 83.3 & 7 & 63.6 \\
\hline $\begin{array}{l}\text { Spontaneous bacterial } \\
\text { peritonitis }\end{array}$ & 4 & 28.6 & 5 & 27.8 & 3 & 27.3 \\
\hline Ascites & 8 & 57.1 & 16 & 88.9 & 9 & 81.8 \\
\hline Splenomegaly & 10 & 71.4 & 11 & 61.1 & 8 & 72.7 \\
\hline Liver size: & & & & & & \\
\hline Normal & 3 & 21.4 & 2 & 11.1 & 4 & 36.4 \\
\hline Enlarged & 2 & 14.3 & 5 & 27.8 & 1 & 9.1 \\
\hline Shrunken & 9 & 64.3 & 11 & 61.1 & 6 & 54.6 \\
\hline
\end{tabular}

$\mathrm{n}=$ total number of patients. 


\begin{tabular}{|c|c|c|c|c|c|c|c|c|}
\hline \multirow[t]{2}{*}{ Variable } & \multicolumn{2}{|c|}{$\begin{array}{l}\text { Control } \\
(n=9)\end{array}$} & \multicolumn{2}{|c|}{$\begin{array}{c}\text { Cirrhosis } \\
(n=14)\end{array}$} & \multicolumn{2}{|c|}{$\begin{array}{c}\text { Hepatic } \\
\text { encephalopathy } \\
\text { stage } 1 \\
(n=18)\end{array}$} & \multicolumn{2}{|c|}{$\begin{array}{c}\text { Hepatic } \\
\text { encephalopathy } \\
\text { stage } 2 \\
(n=11)\end{array}$} \\
\hline & Mean & SD & Mean & SD & Mean & SD & Mean & SD \\
\hline $\begin{array}{l}\text { Ammonia } \\
(\mu \mathrm{mol} / \mathrm{L})\end{array}$ & 28.9 & 9.7 & 105.6 & $10.7^{a}$ & 111.6 & $11.5^{\mathrm{a}}$ & 117.8 & $11.0^{\mathrm{a}}$ \\
\hline$S 100 \beta(\mu \mathrm{g} / \mathrm{L})$ & 0.099 & 0.040 & 0.086 & 0.060 & 0.248 & $0.120^{\mathrm{a}, \mathrm{b}}$ & 0.311 & $0.120^{a, b}$ \\
\hline NSE $(\mu g / L)$ & 12.6 & 1.1 & 13.3 & 2.1 & 13.9 & 1.9 & 14.5 & 2.3 \\
\hline
\end{tabular}

${ }^{a} \mathrm{P}<0.01$ versus control group; ${ }^{b} \mathrm{P}<0.01$ versus cirrhosis group.

$\mathrm{n}=$ total number of patients; $S D=$ standard deviation.

to controls [mean $0.099(\mathrm{SD} 0.04) \mu \mathrm{g} / \mathrm{L}]$ and cirrhosis patients [mean 0.086 (SD 0.06) $\mu \mathrm{g} / \mathrm{L}]$ (Table 2).

Because all the HE patients have underlying cirrhosis, it seemed to be more important and practical to distinguish $\mathrm{HE}$ from cirrhosis rather than from healthy controls. In our study, the sensitivity and the specificity for each value of $\mathrm{S} 100 \beta$ were calculated and then the ROC curve was constructed by plotting the sensitivity against [1-specificity] at each value (Figure 1). At the optimum cut-off point of 0.198 $\mu \mathrm{g} / \mathrm{L}$ the specificity of serum S100 $\beta$ for the

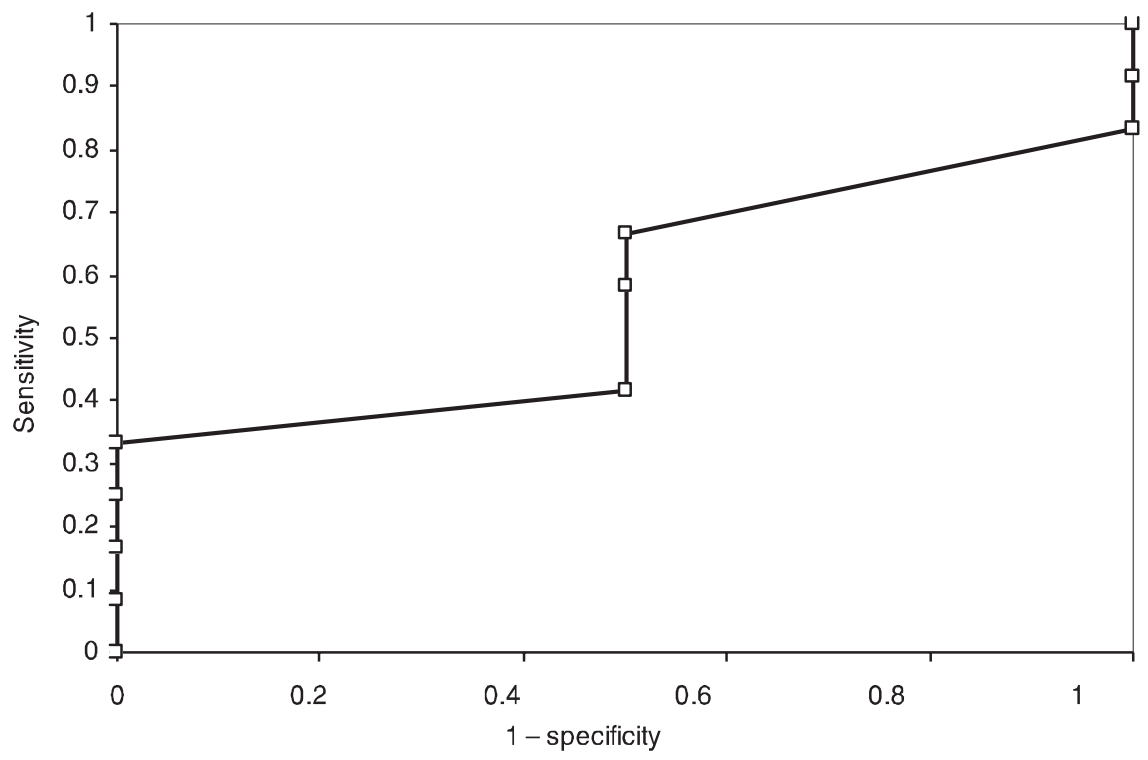

Figure 1 Receiver operating characteristic (ROC) curve for $\mathbf{S 1 0 0 \beta}$ 
a)

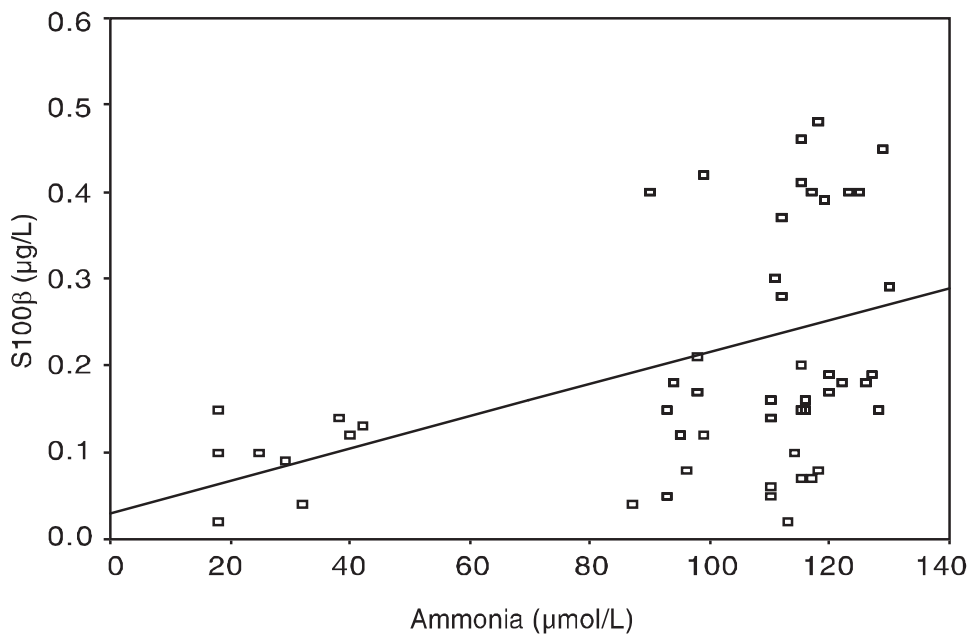

b)

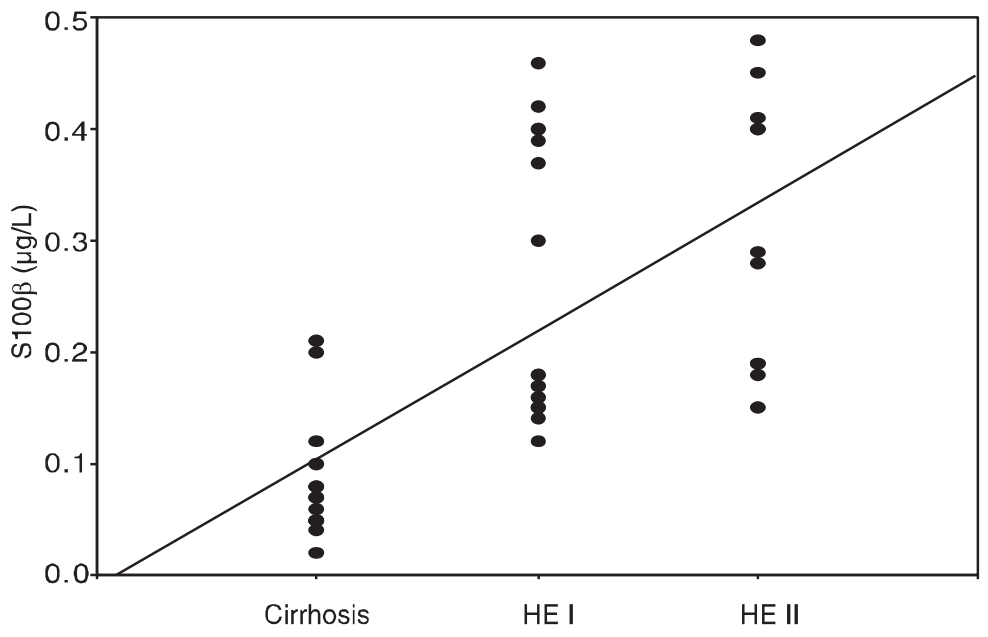

Figure 2 Correlation between $\mathbf{S 1 0 0 \beta}$ level and (a) plasma ammonia level in all diseased groups and (b) stage of cognitive impairment (cirrhosis, hepatic encephalopathy (HE) stage 1 and HE stage 2)

diagnosis of HE was $91.3 \%$ and sensitivity was $51.7 \%$. The positive predictive value, negative predictive value and diagnostic efficiency were $87.5 \%, 58.3 \%$ and $67.3 \%$ respectively.
We observed a significant positive correlation $(r=0.478, P<0.001)$ between plasma ammonia levels and serum S100 $\beta$ concentration in all patients (Figure $2 \mathrm{a}$ ). Also, a significant positive correlation ex- 
isted between $\mathrm{S} 100 \beta$ levels and the stage of cognitive impairment $(r=0.70, P<0.001)$ (Figure 2b).

Serum NSE levels showed a non-significant increase in parallel with the degree of cognitive impairment (Table 2). Values were as follows: control group [mean 12.6 (SD 1.1) $\mu \mathrm{g} / \mathrm{L}]$, cirrhotic patients [mean 13.3 (SD 2.1) $\mu \mathrm{g} / \mathrm{L}$ ], HE stage 1 [mean 13.9 (SD 1.9) $\mu \mathrm{g} / \mathrm{L}$ ] and HE stage 2 [mean 14.5 (SD 2.3) $\mu \mathrm{g} / \mathrm{L}]$.

Plasma ammonia levels $(\mu \mathrm{mol} / \mathrm{L})$ were significantly elevated in cirrhosis patients [mean 105.6 (SD 10.7) $\mu \mathrm{mol} / \mathrm{L}]$, HE stage 1 [mean $111.6(\mathrm{SD} 11.5) \mu \mathrm{mol} / \mathrm{L}$ ] and $\mathrm{HE}$ stage 2 [mean 117.8 (SD 11.0) $\mu \mathrm{mol} / \mathrm{L}$ ] as compared to controls [mean 28.9 (SD 9.7) $\mu \mathrm{mol} / \mathrm{L}](P<0.01)$. However, there was no significant increase in plasma ammonia levels in HE stage 1 and HE stage 2 groups as compared to the cirrhosis group (Table 2).

\section{Discussion}

HE is a diverse group of neuropsychiatric disorders caused by liver dysfunction, usually associated with advanced cirrhosis and portal hypertension. An increased severity of liver disease is associated with decreased physical aspects of quality of life and there is accumulating evidence about the clinical significance of patients with $\mathrm{HE}$ compared to cirrhosis patients who have normal psychometric test performance. At the advanced stage, HE adversely affects both the physical and mental aspects of patients, whereas at stage $1 \mathrm{HE}$ affects mainly the mental aspects, independently of liver disease severity [19].

Dichotomization of the HE group according to West Haven criteria for grading of mental status demonstrated that patients with cognitive deficits showed significantly elevated serum S100ß levels in both HE stage 1 and HE stage 2 groups as compared to controls and cirrhosis patients.

In our study, at the optimum cut-off point of $0.198 \mu \mathrm{g} / \mathrm{L}$ the specificity and sensitivity of serum $\mathrm{S} 100 \boldsymbol{\beta}$ for the diagnosis of HE were $91.3 \%$ and $51.7 \%$ respectively. The positive predictive value, negative predictive value and a diagnostic efficiency were $87.5 \%, 58.3 \% 67.3 \%$ respectively. Accordingly, elevated serum S100 $\beta$ levels reflect only specific aspects of the pathophysiology underlying HE, because a high specificity of serum $\mathrm{S} 100 \beta$ in the diagnosis of $\mathrm{HE}$ is paralleled by a comparatively low sensitivity. Similarly, Wiltfang et al. [20] found that S100 3 levels had a specificity and sensitivity of $100 \%$ and $56.5 \%$ respectively for predicting subclinical portal systemic encephalopathy. They also concluded that although S100 $\beta$ was significantly dependent on the Child-Pugh score, it was more closely related to cognitive impairments than the score.

A significant positive correlation existed between S100 $\beta$ levels and the stage of cognitive impairment $(r=0.70)$. Others found that $\mathrm{S} 100 \beta$ correlated with the severity of brain injury and is a sensitive non-invasive marker of injury [21]. Various stimuli cause astroglial activation resulting in releases of $\mathrm{S} 100 \beta$ by these cells so it is a well established marker for this activation [22].

Elevated serum S100ß levels in HE can be used as a noninvasive marker of disturbances in BBB function and brain lesions $[15,16]$. Massive elevations in $\mathrm{S} 100 \beta$ are indicators of prior brain damage and can be used to differentiate extensive damage from minor, transient impairment. This can in part be explained by subtle post-traumatic impairments of the BBB [23]. S100 $\beta$ is involved in the regulation of energy metabolism in brain cells. It modulates the proliferation and the differentiation of neu- 
rons and glia. Furthermore, it interacts with many immunological functions of the brain. Quite clearly, S100ß exerts a protective effect as long as it is kept within the cells at physiological levels. However, once it is secreted or released, its local concentration dictates its beneficial or detrimental effects. Nanomolar concentrations appear to exert neuroprotective effects while micromolar concentrations produce neurodegenerative or apoptosis-inducing effects [24].

A number of routes of $\mathrm{S} 100 \beta$ leakage into the peripheral circulation have been suggested. One possible route consists of disruption of the brain-CSF interface, leading to increased levels of S100 $\beta$ in CSF that are reabsorbed into the cerebral venous system. A second, more direct route is provided by disruptions on the capillary level that allow drainage of perivascular $\mathrm{S} 100 \beta$ directly into the circulation [15]. The second route is more likely in patients with brain tumours or other lesions [16].

Serum NSE levels showed a non-significant increase in parallel with cognitive impairment in HE. We conclude that serum NSE has no value in diagnosis of $\mathrm{HE}$ in cirrhotic patients as it did not show a significant difference between the diseased groups. Others found that NSE was only slightly higher in patients with mild traumatic brain injury whereas S100 $\beta$ levels were significantly higher [25]. NSE does not seem to act as a peripheral marker of brain damage and BBB dysfunction [15]. In Parkinson's disease, Schaf et al. concluded that S100 $\beta$ and NSE levels were not useful diagnostic markers, but that $S 100 \beta$ may be a signal of disease progression [26].

Plasma ammonia levels $(\mu \mathrm{mol} / \mathrm{L})$ were elevated in cirrhotic patients, HE stage 1 and HE stage 2 as compared to controls.
However, there was no significant increase in plasma ammonia levels in HE stage 1 and stage 2 groups as compared to the cirrhosis group. We observed a significant positive correlation $(r=0.478, P<0.001)$ between plasma ammonia levels and serum S100ß concentration in all patients. This contrasts with the results of Wiltfang et al. who did not observe any correlation between arterial ammonia levels and serum S100 $\beta$ concentration [20]. Despite the significant correlation between the partial pressure of ammonia and HE, Nicolao et al. suggested that neither was more useful clinically than venous ammonia levels and that all 3 have a limited role in the diagnosis of HE and clinical management [27].

Due to the high prevalence of liver diseases in Egypt, early diagnosis of HE in cirrhosis patients is of great importance to allow proper management of HE patients, thus preventing further deterioration of their mental status. Serum S100ß increased with progression of $\mathrm{HE}$, indicating that enhanced cerebral release due to $\mathrm{HE}$ and impaired metabolism due to liver cirrhosis may act synergistically in elevating serum $\mathrm{S} 100 \beta$. Moreover, $\mathrm{S} 100 \beta$ is clearly superior to NSE and ammonia in terms of diagnostic value in HE. While S100 $\beta$ seems to be a promising biochemical surrogate marker for mild cognitive impairment due to $\mathrm{HE}$, studies with repetitive measurements of serum $\mathrm{S} 100 \beta$ are not yet available. Future studies will be valuable to determine to what extent a systematic displacement of serum $\mathrm{S} 100 \beta$ is influenced by therapeutic strategies and to investigate the relation of serum S100 $\beta$ to the etiology of liver disease (hepatocellular versus/cholestatic and $\mathrm{HCV}$ versus non-HCV). 


\section{References}

1. Arguedas MR, Delawrence TG, Mcguire BM. Influence of hepatic encephalopathy on health-related quality of life in patients with cirrhosis. Digestive diseases and sciences, 2003, 48:1622-6.

2. Butterworth RF The neurobiology of hepatic encephalopathy. Seminars in liver disease, 1996, 16:235-44.

3. Albrecht J, Jones EA Hepatic encephalopathy: molecular mechanisms underlying the clinical syndrome. Journal of the neurological sciences, 1999, 170:13846.

4. Moore BW. A soluble protein characteristic of the nervous system. Biochemical and biophysical research communications, 1965, 19:739-44.

5. Jönsson $\mathrm{H}$ et al. Elimination of $\mathrm{S} 100 \beta$ and renal function after cardiac surgery. Journal of cardiothoracic and vascular anesthesia, 2000, 14:698-701.

6. Donato R. S100: a multigenic family of calcium-modulated proteins of the EFhand type with intracellular and extracellular functional roles. International journal of biochemistry \& cell biology, 2001, 33:637-68.

7. Adami C et al. S100B expression in and effects on microglia. Glia, 2001, 33:13142.

8. Ghanem $G$ et al. On the release and half-life of $S 100 \beta$ protein in the peripheral blood of melanoma patients. International journal of cancer, 2001, 94:586-90.

9. Barger SW, Van Eldik LJ. S100 $\beta$ stimulates calcium fluxes in glial and neuronal cells. Journal of biological chemistry, 1992, 267:9689-94.

10. Schmechel D et al. Neuron-specific enolase is a molecular marker for peripheral and central neuroendocrine cells. Nature, 1978, 276:834-6.
11. Skogseid IM et al. Increased serum creatine kinase BB and neuron specific enolase following head injury indicates brain damage. Acta neurochirurgica, 1992, 115:106-11.

12. Vazquez $M$ et al. Creatine kinase BB and neuron specific enolase in cerebrospinal fluid in the diagnosis of brain insult. American journal of forensic medicine and pathology, 1995, 16:210-4.

13. Yamazaki $Y$ et al. Diagnostic significance of serum neuron-specific enolase and myelin basic protein assay in patients with acute head trauma. Surgical neurology, 1995, 43:267-71.

14. Norenberg M. Astrocytic ammonia interactions in hepatic encephalopathy. Seminars in liver disease, 1996, 16:245-53.

15. Marchi $\mathrm{N}$ et al. Peripheral markers of brain damage and blood-brain barrier dysfunction. Restorative neurology and neuroscience, 2003, 21(3-4):109-21.

16. Kanner AA et al. Serum S100beta: a noninvasive marker of blood-brain barrier function and brain lesions. Cancer, 2003, 97:2806-13.

17. Berger $R$ et al. Neuron-specific enolase and S100B in cerebrospinal fluid after severe traumatic brain injury in infants and children. Pediatrics, 2002, 109(2):e31.

18. Ferenci $P$ et al. Hepatic encephalopathy-definition, nomenclature, diagnosis, and quantification: final report of the working party at the 11th World Congresses of Gastroenterology, Vienna, 1998. Hepatology, 2002, 35:716-21.

19. Rössle $M$ et al. The first decade of the transjugular intrahepatic portosystemic shunt (TIPS): state of the art. Liver, 1998, 18:73-89.

20. Wiltfang $J$ et al. Elevated serum levels of astroglial S100beta in patients with liver 
cirrhosis indicate early and subclinical portal-systemic encephalopathy. Metabolic brain disease, 1999, 14:239-51.

21. Savola $O$ et al. Effects of head and extracranial injuries on serum protein S100B levels in trauma patients. Journal of trauma, 2004, 56(6):1229-34.

22. Stranjalis $G$ et al. Serum S-100B as an indicator of early postoperative deterioration after meningioma surgery. Clinical chemistry, 2005, 51(1):202-7.

23. Szumanska G, Albrecht J. Lectin histochemistry of the rat brain following thioacetamide-induced hepatic failure. Molecular and chemical neuropathology, 1997, 32:163-77.

24. Rothermundt M et al. S100B in brain damage and neurodegeneration. Microscopy research and technique, 2003, 60:61432.

25. De Kruijk JR et al. S-100B and neuronspecific enolase in serum of mild traumatic brain injury patients. A comparison with health controls. Acta neurologica scandinavica, 2001, 103(3):175-9.

26. Schaf DV et al. S100B and NSE serum levels in patients with Parkinson's disease. Parkinsonism \& related disorders, 2005, 11(1):39-43.

27. Nicolao $\mathrm{F}$ et al. Role of determination of partial pressure of ammonia in cirrhotic patients with and without hepatic encephalopathy. Journal of hepatology, 2003, 38(4):441-6.

\section{Mote from the Editor}

We wish to draw the kind attention of our potential authors to the importance of applying the editorial requirements of the EMHJ when preparing their manuscripts for submission for publication. These provisions can be seen in the Guidelines for Authors, which are published at the end of every issue of the Journal in Arabic, English and French. We regret that we are unable to accept papers that do not conform to the editorial requirements. 